\title{
DSC Studies on Hydrogen Bonding of Poly(4-hydroxy-3, 5-dimethoxystyrene) and Related Derivatives
}

\author{
Kunio Nakamura, Tatsuko Hatakeyama, ${ }^{*}$ and Hyoe Hatakeyama** \\ Industrial Research Institute of Kanagawa Prefecture, \\ 3173, Showa-machi, Kanazawa-ku, Yokohama 236, Japan \\ * Research Institute for Polymers and Textiles, \\ Yatabe-Higashi, Tsukuba, Ibaraki 305, Japan \\ **Industrial Products Research Institute, \\ Yatabe-Higashi, Tsukuba, Ibaraki 305, Japan
}

(Received June 18, 1985)

\begin{abstract}
Poly(4-acetoxystyrene) ( $\left.\mathrm{P}_{\mathrm{p}} \mathrm{AS}\right)$, poly(4-acetoxy-3-methoxystyrene) (PAMS), poly(4-acetoxy-3,5-dimethoxystyrene) (PADMS), poly(4-hydroxystyrene) $\left(\mathrm{P}_{\mathrm{p}} \mathrm{HS}\right)$, poly(4-hydroxy3-methoxystyrene) (PHMS), poly(4-hydroxy-3,5-dimethoxystyrene) (PHDMS) and partially hydrolyzed acetate polymers were prepared. The effects of hydrogen bonding on the glass transition temperature $\left(T_{\mathrm{g}}\right)$ and heat capacity $\left(C_{\mathrm{p}}\right)$ of the above polymers were studied by differential scanning calorimetry (DSC). The glass transition temperatures of partially hydrolyzed $P_{p} A S$ and PAMS increased with the degree of hydrolysis. However, in the case of partially hydrolyzed PADMS, initially $T_{\mathrm{g}}$ increased with the degree of hydrolysis and then decreased with increasing hydrolysis. Thermal analysis of water sorbed on the polymers showed that the bound water content of PHDMS was larger than that of $\mathrm{P}_{\mathrm{p}} \mathrm{HS}$ and PHMS. Taking the bound water content as an indication of the hydrogen bonds of each polymer, it was ascertained that the molecular motion related to hydrogen bonding was effected by the chemical structure of each polymer.
\end{abstract}

KEY WORDS Polyhydroxystyrene / Poly(4-hydroxy-3,5-dimethoxystyrene) / Substituent / Hydrogen Bond / Water / Bound Water / Glass Transition / Heat Capacity / Differential Scanning Calorimetry /

The molecular motion of polymers is known to be restricted by hydrogen bonds formed between main chains and side chains. Barb ${ }^{1}$ reported the phase transition-temperature of mono-substituted polystyrene derivatives and suggested that the hydrophilic group introduced into the aromatic ring increased thermal stability of polymer. In our studies on the hydrogen bonding of polyhydroxystyrene derivatives, ${ }^{2-9}$ it was clarified that stability of the polymers is effected by the type, number and location of substituent groups in an aromatic ring. When more than two substituent groups are introduced into an aromatic ring, co-operative contribution is especially important

In the previous papers, ${ }^{2-5}$ we reported the thermal properties of the styrene derivatives, poly(4-hydroxystyrene) ( $\left.\mathrm{P}_{\mathrm{p}} \mathrm{HS}\right)$, poly(4-hydroxy-3-methoxystyrene) (PHMS) and styrene-4-hydroxystyrene (St-HS) copolymers. The glass transition temperatures $\left(T_{\mathrm{g}}\right)$ of these styrene derivatives are $c a$. 20 to $80 \mathrm{~K}$ higher than that of polystyrene. These styrene derivatives have been. found biodegradable ${ }^{10}$ and have some advantageous mechanical properties, especially high strength compared with that of polystyrene. ${ }^{8}$ These results have been attributed to the hydrogen bonds formed between hydroxyl groups of these polystyrene derivatives. Moreover, we studied the effects of the location of hydroxyl groups in the aromatic ring on the formation of hydrogen bonding between the polyhydroxystyrene de- 
rivatives. It was clarified that the readiness of the formation of hydrogen bonding was in the order of 3,4,2-positions of the aromatic ring. ${ }^{7}$

In this study, poly(4-acetoxystyrene) $\left(\mathrm{P}_{\mathrm{p}^{-}}\right.$AS), poly(4-acetoxy-3-methoxystyrene) (PAMS), poly(4-acetoxy-3,5-dimethoxystyrene)(PADMS), poly(4-hydroxystyrene) ( $\left.\mathrm{P}_{\mathrm{p}} \mathrm{HS}\right)$, poly(4-hydroxy-3-methoxystyrene) (PHMS), poly(4-hydroxy-3,5-dimethoxystyrene) (PHDMS) and patially hydrolyzed acetate polymers were prepared and contained hydrophilic hydroxyl and hydrophobic methoxyl groups in the aromatic rings of polystyrene. The effects of hydrogen bonding on the glass transition temperatures $\left(T_{\mathrm{g}}\right)$ and heat capacity $\left(C_{\mathrm{p}}\right)$ of these polymers were studied by differential scanning calorimetry (DSC). The phase transition of water sorbed on the polymers was also measured by DSC. The relationship between bound water content as an indication of hydrogen bonds and chemical structure of the polymer, especially the combination of substituent groups, was studied.

\section{EXPERIMENTAL}

\section{Sample Preparation}

4-Hydroxy-3,5-dimethoxystyrene Monomer $(H D M S)$. Sinapic acid was prepared by the interaction of syringaldehyde $(10 \mathrm{~g})$ with malonic acid $(10 \mathrm{~g})$ in the presence of piperidine $(1 \mathrm{ml})$ in $10 \mathrm{ml}$ pyridine for about $20 \mathrm{~h}$ at $60^{\circ} \mathrm{C}$. The product was precipitated with a $5 \%$ $\mathrm{HCl}$ solution and recrystallized from water containing a small amount of methanol. Sinapic acid $(10 \mathrm{~g})$, freshly prepared precipitated copper $(0.2 \mathrm{~g})$ and hydroquinone $(0.3 \mathrm{~g})$ were added to quinoline $(15 \mathrm{ml})$. The mixture was then heated at $200^{\circ} \mathrm{C}$ under a nitrogen atmosphere until the evolution of carbon dioxide subsided. The crude mixture was distilled under reduced pressure $(0.1 \mathrm{mmHg})$. The fraction boiling at $110^{\circ} \mathrm{C}$ was collected. The crude HDMS obtained was added to a cold $1 \mathrm{~N}$ hydrochloric acid solution, extracted by ethyl ether, dried with anhydrous sodium sulphate and purified by distillation

4-Acetoxy-3,5-dimethoxystyrene Monomer $(A D M S)$. ADMS was prepared from HDMS $(5 \mathrm{~g})$ by acetylation with the mixture of pyridine $(30 \mathrm{ml})$ and acetic anhydride $(20 \mathrm{ml})$. A white oil was obtained.

Poly(4-acetoxy-3,5-dimethoxystyrene) (PA$D M S)$. Poly(4-acetoxy-3,5-dimethoxystyrene) (PADMS) was obtained by bulk polymerization using $1 \%$ of $2,2^{\prime}$-azobisisobutyronitrile (AIBN) as an initiator for $2 \mathrm{~h}$ at $80^{\circ} \mathrm{C}$. PHDMS was prepared by the hydrolysis of PADMS. Partially hydrolyzed PADMSs were prepared as follows: PADMS (2g) was dissolved in $200 \mathrm{ml}$ of acetone and concentrated hydrochloric acid $(4 \mathrm{ml})$ was stirred into this solution. The mixture was allowed to stand for various time intervals ( 1 to $24 \mathrm{~h}$ ) at $65^{\circ} \mathrm{C}$. The resulting mixture was stirred slowly into a large amount of ice cold water, filtered, repeatedly washed with water, and then dried in air.

Poly(4-hydroxystyrene) ( $\left.\mathrm{P}_{\mathrm{p}} \mathrm{HS}\right)$, poly(4-acetoxy-styrene) ( $\left.\mathrm{P}_{\mathrm{p}} \mathrm{AS}\right)$, partially hydrolyzed $\mathrm{P}_{\mathrm{p}} \mathrm{ASs}$, poly(4-hydroxy-3-methoxystyrene) (PHMS), poly(4-acetoxy-3-methoxystyrene)(PAMS) and partially hydrolyzed PAMSs were prepared by essentially the same method as in the case of PHDMS reported previously. ${ }^{3,6}$

\section{Measurements}

Gel Permeation Chromatography (GPC). The molecular weight $\left(M_{w}\right)$ and distribution $\left(M_{w} / M_{n}\right)$ of the polymers were obtained with a Toyo Soda gel germeation chromatograph, Model HLC-801. The chromatograph was calibrated by plotting the molecular weight of monodisperse polystyrene (Pressure Chemical Co.) against the elution volume. Values of $M_{w}$ and $M_{w} / M_{n}$ were $1.0 \times 10^{5}$ and 3.1 for $\mathrm{P}_{\mathrm{p}} \mathrm{As}$, $9.8 \times 10^{4}$ and 2.8 for $\mathrm{P}_{\mathrm{p}} \mathrm{HS}, 2.2 \times 10^{5}$ and 3.2 for PAMS, $1.0 \times 10^{5}$ and 3.0 for PHMS, $1.1 \times$ $10^{5}$ and 4.1 for PADMS, $9.9 \times 10^{4}$ and 3.7 for PHDMS, respectively.

Infrared Spectroscopy (IR). A Nihon-Bunko Model IR-G infrared spectrophotometer was 
used for the determination. The degree of hydrolysis of each polymer was calculated using the equation reported previously. ${ }^{3}$

Differential Scanning Calorimetry (DSC). The glass transition temperature $\left(T_{\mathrm{g}}\right)$ and phase transition of sorbed water were measured with a Du Pont 910 DSC. The glass transitions temperatures of the polymers were measured using an aluminium open pan under a dry nitrogen atomosphere. $T_{\mathrm{g}}$ was determined from the DSC curve as the intersection of the extension of the base line with a line tangent to the maximum slope of the endothermic peak. The bound water content of each polymer was measured by a method similar to that reported previously; ${ }^{11}$ i.e., the water content was evaluated from the enthalpy of melting. However, an aluminium open pan was used for the measurement in this experiment. Therefore, the total water content was calculated from the enthalpy of vaporization obtained from the DSC curves instead of measuring the sample weight in a sealed pan. In order to avoid experimental errors, DSC runs were repeated three times in each experiment. The DSC curves were obtained at a scanning rate of $10 \mathrm{~K} \mathrm{~min}^{-1}$. The melting, crystallization and vaporization enthalpies were calculated by reference to the enthalpy of pure water.

The aluminium sample pans were previously exposed to steam in an autoclave at $120^{\circ} \mathrm{C}$ for $3 \mathrm{~h}$ to eliminate the formation of aluminium hydroxide during measurements. The samples were first dried in a vacuum desiccator for about one week and then about a $5 \mathrm{mg}$ sample was weighed. For measurement of polymers containing sorbed water, small amounts of water were added with a microsyringe and the total weight was then measured on a microbalance. If the water content exceeded the predetermined amount, the sample pan was allowed to stand for a few minutes until the water evaporated. The water content was calculated from the following equation,

Water content $=$ Weight of Added Water $/$ Weight of Dry Sample $\times 100(\%)$.
The heat capacity $\left(C_{\mathrm{p}}\right)$ of dry samples was measured with a Perkin-Elmer DSC model II by a similar method reported previously. ${ }^{12,13}$ In this experiment, an open pan was used.

\section{RESULTS AND DISCUSSION}

Table I shows the degree of hydrolysis $\left(D_{\mathrm{h}}\right)$ measured by IR, glass transition temperature $\left(T_{\mathrm{g}}\right)$ measured by DSC, molecular weight of monomer unit $(M)$ calculated from $\mathrm{Dh}$, bound water content $\left(C_{\mathrm{b}}\right)$ measured by DSC, and bound water content per monomer unit of each polymer $\left(B_{\mathrm{m}}\right)$ calculated from $M$ and $C_{\mathrm{b}}$. It can be seen from Table I that the $T_{\mathrm{g}}$ and bound water content are related to the degree of hydrolysis, i.e., the number of hydroxyl groups of each polymer.

The relationship between the degree of hydrolysis and the glass transition temperatures of the polymers is shown in Figure 1. The glass transition temperatures of partially hydrolyzed $\mathrm{P}_{\mathrm{p}} \mathrm{AS}$ and PAMS increase almost linearly with hydrolysis. The glass transition temperatures of $\mathrm{P}_{\mathrm{p}} \mathrm{HS}$, and PHMS obtained from $100 \%$ hydrolyzed $\mathrm{P}_{\mathrm{p}} \mathrm{AS}$ and PAMS are $182^{\circ} \mathrm{C}$ and $142^{\circ} \mathrm{C}$, respectively. With increasing degree of hydrolysis, the acetoxyl groups are substituted by the hydroxyl groups and accordingly, hydrogen bonds easily form between hydroxyl groups. However the presense of the hydrophobic methoxyl groups attached to the 3-positions of the aromatic rings decreases $T_{\mathrm{g}}$ in the case of partially hydrolyzed PAMS compared with the case of partially hydrolyzed $\mathrm{P}_{\mathrm{p}} \mathrm{AS}$. Barb ${ }^{1}$ pointed out in his study of the glass transition temperature $\left(T_{\mathrm{g}}\right)$ of monosubstituted polystyrene derivatives that $T_{\mathrm{g}}$ decreases on introduction of a substituent group at the 3 -position in a aromatic ring.

The glass transition temperatures of partially hydrolyzed PADMS increase with a small degree of hydrolysis and then decrease gradually as hydrolysis increases. $T_{\mathrm{g}}\left(132^{\circ} \mathrm{C}\right)$ of PADMS is higher than the glass transition 
Table 1. Characteristic values of the samples

\begin{tabular}{|c|c|c|c|c|c|}
\hline Sample & $D_{\mathrm{h}} / \%$ & $T_{\mathrm{g}} /{ }^{\circ} \mathrm{C}$ & $\mathbf{M}$ & $C_{\mathrm{b}} / \%$ & $B_{\mathrm{m}} / \mathrm{mol}$ \\
\hline \multirow{7}{*}{$\mathrm{P}_{\mathrm{p}} \mathrm{AS}$} & 0 & 112 & 162 & 3.1 & 0.28 \\
\hline & 8 & 123 & 159 & 3.7 & 0.33 \\
\hline & 22 & 133 & 153 & 3.6 & 0.31 \\
\hline & 49 & 153 & 141 & 5.2 & 0.41 \\
\hline & 62 & 160 & 136 & 5.7 & 0.43 \\
\hline & 76 & 171 & 130 & 6.6 & 0.48 \\
\hline & 95 & 179 & 122 & 10.3 & 0.70 \\
\hline $\mathrm{P}_{\mathrm{p}} \mathrm{HS}$ & 100 & 182 & 120 & 10.8 & 0.72 \\
\hline \multirow[t]{7}{*}{ PAMS } & 0 & 115 & 192 & 2.0 & 0.21 \\
\hline & 17 & 122 & 185 & 3.4 & 0.35 \\
\hline & 29 & 127 & 180 & 5.1 & 0.51 \\
\hline & 61 & 134 & 166 & 10.9 & 1.01 \\
\hline & 76 & 139 & 160 & 12.8 & 1.14 \\
\hline & 89 & 139 & 155 & 14.4 & 1.24 \\
\hline & 97 & 144 & 151 & 16.4 & 1.38 \\
\hline PHMS & 100 & 142 & 150 & 16.3 & 1.36 \\
\hline \multirow[t]{8}{*}{ PADMS } & 0 & 132 & 222 & 2.6 & 0.32 \\
\hline & 5 & 142 & 220 & 3.3 & 0.40 \\
\hline & 14 & 147 & 216 & 3.8 & 0.46 \\
\hline & 29 & 139 & 210 & 8.5 & 0.99 \\
\hline & 39 & 135 & 206 & 10.5 & 1.20 \\
\hline & 69 & 129 & 193 & 16.5 & 1.77 \\
\hline & 84 & 126 & 187 & 21.0 & 2.18 \\
\hline & 93 & 121 & 183 & 22.9 & 2.33 \\
\hline PHDMS & 100 & 108 & 180 & 27.9 & 2.79 \\
\hline
\end{tabular}

" $D_{\mathrm{h}}=$ degree of hydrolysis; $T_{\mathrm{g}}=$ glass transition temperature; $\mathbf{M}=$ molecular weight of monomer unit; $C_{\mathrm{b}}=$ bound water content; $B_{\mathrm{m}}=$ bound water content per monomer unit.

temperatures of $\mathrm{P}_{\mathrm{p}} \mathrm{AS}\left(112^{\circ} \mathrm{C}\right)$ and PAMS $\left(115^{\circ} \mathrm{C}\right)$. This indicates that the molecular motion of main chain of PADMS is depressed by the methoxyl groups which are attached symmetrically at both sides of the hydroxyl group at the 4-position of an aromatic ring. Moreover, it is considered that the main chain motion of PADMS is prevented by three large substituent groups, i.e., two methoxyls groups and an acetoxyl group. Therefore, $T_{\mathrm{g}}$ of PADMS is $40 \mathrm{~K}$ higher than that of polystyren $\left(92^{\circ} \mathrm{C}\right)$. The increase of $T_{\mathrm{g}}$ with a slight hydrolysis is due to the weak hydrogen bonding between the acetoxyl and hydroxyl groups. The decrease of $T_{\mathrm{g}}$ with much hydrolysis is attributed to the small hydrophilic hy-

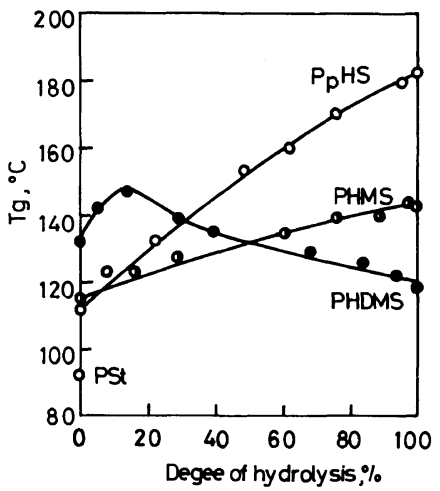

Figure 1. The relationship between glass transition temperatures $\left(T_{\mathrm{g}}\right)$ and degree of hydrolysis of partially hydrolyzed $\mathrm{P}_{\mathrm{p}} \mathrm{AS}(\mathrm{O})$, PAMS ( $)$, and PADMS (O).

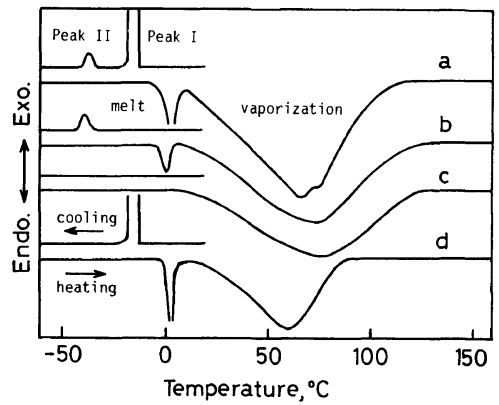

Figure 2. DSC curves of water sorbed on $\mathrm{P}_{\mathrm{p}} \mathrm{HS}$ measured using an aluminium open pan. Scanning rate was $10 \mathrm{~K} \mathrm{~min}^{-1}$ and sample weight was about $5 \mathrm{mg}$. The amounts of sorbed water calculated from the enthalpies of vaporization curves are: a, $27.9 \%, b, 9.8 \%, c, 7.8 \%$, and $\mathrm{d}$, pure water.

droxyl group which is located between two large methoxyl groups; that is, the hydroxyl groups cannot form hydrogen bonds owing to the steric hindrance of methoxyl groups.

We reported in a previous paper ${ }^{5}$ that the bound water is defined as water molecules which act to break the hydrogen bonding and then attach closely to hydroxyl groups of the polymers. In this study, we also measured crystallization, melting and vaporization of water sorbed on $\mathrm{P}_{\mathrm{p}} \mathrm{HS}$ using DSC. Figure 2 shows the DSC curves of water sorbed on $\mathrm{P}_{\mathrm{p}} \mathrm{HS}$ measured with Du Pont 910 DSC using open pans. In general, when a sample containing sorbed water is cooled from room 
temperature to $-100^{\circ} \mathrm{C}$, two exothermic peaks of crystallization of water are observed (curve a). One is a sharp peak (Peak I) observed at about $-15^{\circ} \mathrm{C}$; the other is a broad small peak (Peak II) observed at about $-35^{\circ} \mathrm{C}$. However, the first-order transition of water is not observed unless the water content exceeds a certain amount (curve c). After exceeding this water content, Peak II appears at about $-35^{\circ} \mathrm{C}$ (curve b). The shape and temperature of Peak I accord well with those for the crystallization of pure water (curve d). The melting of water sorbed on $\mathrm{P}_{\mathrm{p}} \mathrm{HS}$ starts from a temperature lower than that of pure water. However, the melting of water is not observed when a small amount of water is sorbed on the sample (curve c). The vaporization curve of sorbed water was continuously observed in the higher temperature region than at the melting temperature of water. The vaporization of sorbed water is usually observed even if the crystallization and melting of water are not observed (curve c). The shapes and temperatures of the phase transition curves of water vary depending on the water content, kind of samples, chemical structure and number of hydroxyl groups. For example, the end temperatures of vaporization of water sorved on $\mathrm{P}_{\mathrm{p}} \mathrm{HS}, \mathrm{PHMS}, \mathrm{PHDMS}$ and pure water were $112^{\circ} \mathrm{C}, 110^{\circ} \mathrm{C}, 94^{\circ} \mathrm{C}$, and $81^{\circ} \mathrm{C}$, respectively.

Bound water content $\left(C_{\mathrm{b}}\right)$ and the number of moles of bound water attached to a monomer unit of the polymer $\left(B_{\mathrm{m}}\right)$ were calculated from the following equations:

$$
C_{\mathrm{b}}=\left(W_{\mathrm{c}}-W_{\mathrm{f}}\right) / W_{\mathrm{s}} \times 100(\%)
$$

or

$$
C_{\mathrm{b}}=\left(W_{\mathrm{nf}}+W_{\mathrm{p} 2}\right) / W_{\mathrm{s}} \times 100(\%)
$$

and

$$
B_{\mathrm{m}}=M C_{\mathrm{b}} / 100 / 18(\mathrm{~mol})
$$

where, $W_{\mathrm{c}}(\mathrm{mg})$ is total added water, $W_{\mathrm{f}}(\mathrm{mg})$ is free water (Peak I), $W_{\mathrm{s}}(\mathrm{mg})$ is the weight of dry sample, $W_{\mathrm{nf}}(\mathrm{mg})$ is nonfreezing water, $W_{\mathrm{p} 2}(\mathrm{mg})$ is feezable bound water (Peak II),
$M$ is the molecular weight of monomer unit of the polymer and 18 is the molecular weight of water. The detailed explanation of bound water was reported previously. $C_{\mathrm{b}}$ and $B_{\mathrm{m}}$ determined by the enthalpy of the phase transition of water sorbed on each sample are listed in Table I. The bound water content of each polymer increased with the degree of hydrolysis. The increase of bound water owing to the hydrolysis of PHDMS was the largest, that of PHMS next and that of $\mathrm{P}_{\mathrm{p}} \mathrm{HS}$, the smallest. These three polymers have one hydroxyl group per monomer unit. Therefore, in the case of $\mathrm{P}_{\mathrm{p}} \mathrm{HS}$, water molecules are restricted by the hydroxyl groups. However, it is suggested that in the cases of PHMS and PHDMS, water molecules are restricted not only by hydroxyl groups but also by other steric effects.

Figure 3 shows the relationship between bound water content per monomer unit $\left(B_{\mathrm{m}}\right)$ and the degree of hydrolysis of each partially hydrolyzed acetate polymer. The number of mol of bound water attached to the monomer unit increases with hydrolysis. The increase of bound water is from $0.28 \mathrm{~mol}$ to $0.72 \mathrm{~mol}$ for $\mathrm{P}_{\mathrm{p}} \mathrm{HS}$, from 0.21 to 1.36 for PHMS and 0.32 to 2.79 for PHDMS, respectively. These acetate polymers, $P_{p} A S$, PAMS and PADMS, have almost the same bound water content of about $0.3 \mathrm{~mol}$ per monomer unit. We reported previously ${ }^{5}$ that the bound water content of hydrophobic polymers such as polystyrene (PSt) was zero. This indicates that these acetates are weakly hydrophilic polymers, i.e., these polymers have very weak hydrogen bonds owing to the $\mathrm{C}=\mathrm{O}$ bond in the acetoxyl group. This is also supported by the fact that the glass transition temperatures of these acetate polymers are higher than that of PSt.

As shown in Figure 3, the amount of bound water increases with hydrolysis. However, the rate of increase varies for each sample. The amount of bound water of a completely hydrolyzed sample is $0.72 \mathrm{~mol}$ for $\mathrm{P}_{\mathrm{p}} \mathrm{HS}, 1.36$ for 


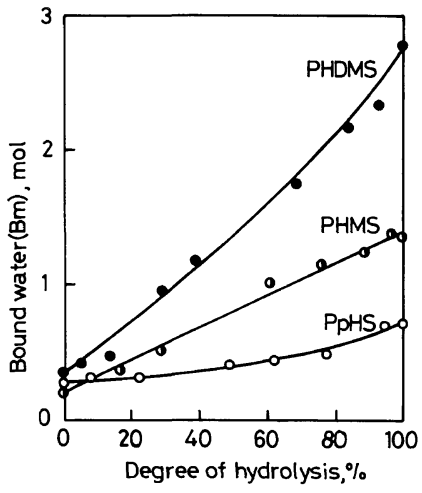

Figure 3. The relationship between bound water content per monomer unit of the polymers and degree of hydrolysis of partially hydrolyzed $\mathrm{P}_{\mathrm{p}} \mathrm{AS}(\mathrm{O})$, PAMS (O), and PADMS (O

PHMS and 2.79 for PHDMS. The differences in these values cannot be explained solely by the existence of hydroxyl groups. However, the effects of the methoxyl groups seem very large. With regard to the chemical structure of a hydrolyzed polymer, the hydroxyl or acetoxyl group is located at the 4-position and methoxyl group is located at 3- and/or 5position of the aromatic ring for each polymer. The different amounts of bound water among polymers are hard to explain if we consider only the restriction of water molecules by hydroxyl groups. It is therefore reasonable to take into account the location of methoxyl groups, which afford space where water molecules sterically interact with the hydroxyl and methoxyl groups of the polymers. This indicates that the bound water is markedly influenced by hydrophilic and hydrophobic group combinations in an aromatic ring of the polymers.

In the case of PHDMS, the glass transition temperatures of polymers having different degrees of hydrolysis show maximum values at about $14 \%$ as shown in Figure 1. On the other hand, bound water content of these polymers increases linearly as shown in Figure 3. In the cases of $\mathrm{P}_{\mathrm{p}} \mathrm{HS}$ and PHMS, hydrogen bonding between main chains can

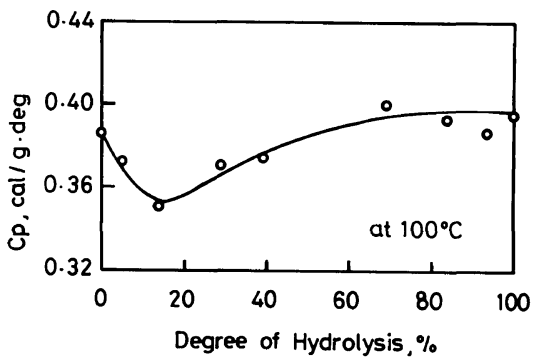

Figure 4. The relationship between heat capacities $\left(C_{\mathrm{p}}\right)$ at $100^{\circ} \mathrm{C}$ and the degree of hydrolysis of PADMS.

easily occur as the number of hydroxyl groups increases. With regard to differences between the result obtained in this experiment and those previously reported, ${ }^{3,5,7}$ it is important to take into consideration the higher order structure of PHDMS.

Figure 4 shows the relationship between the heat capacity $\left(C_{\mathrm{p}}\right)$ at $100^{\circ} \mathrm{C}$ and the degree of hydrolysis of PADMS. $C_{\mathrm{p}} \mathrm{s}$ were carefully measured after annealing at $180^{\circ} \mathrm{C}$ for $10 \mathrm{~min}$ in order to avoid moisture absorption during holding. It can be seen from Figure 4 that $C_{\mathrm{p}} \mathrm{s}$ of partially hydrolyzed PADMS decrease from 0.39 to $0.35 \mathrm{cal} \mathrm{g}^{-1} \mathrm{deg}^{-1}$ until about $14 \%$ of the hydrolysis and then increase gradually from 0.35 to $0.40 \mathrm{cal} \mathrm{g}^{-1} \mathrm{deg}^{-1}$ with hydrolysis. The $C_{\mathrm{p}}$ of PHDMS being about $14 \%$ of the hydrolysis indicates a minimum value. This minimum $C_{\mathrm{p}}$ value corresponds to the maximum $T_{\mathrm{g}}$ value of partially hydrolyzed PADMS. These facts suggest that the higher order structure varies with degree of hydrolysis and that the packing density of main chains of PHDMS having $14 \%$ of the hydrolysis shows the highest value among all samples. Therefore, the molecular motion of main chain of $14 \%$ hydrolyzed PHDMS is strongly prevented and accordingly $T_{\mathrm{g}}$ of the polymer indicates the highest value.

From the above results, it is concluded that the hydroxyl groups in hydrolyzed $\mathrm{P}_{\mathrm{p}} \mathrm{AS}$, PAMS and PADMS have important roles in hydrogen bonding. The molecular motion of these polymers is prevented by increasing the 
number of hydrogen bonds between the main chains. The differences among the glass transition temperatures of $\mathrm{P}_{\mathrm{p}} \mathrm{HS}$, PHMS and PHDMS are due to the methoxyl groups introduced into the 3- and/or the 5-positions of the aromatic rings of these polystyrene derivatives. Moreover, bound water molecules are restricted not only by hydroxyl groups but by steric interactions between the hydroxyl and methoxyl groups. The heat capacities are dependent on the conformation of these polymers which are strongly influenced by hydrogen bonding.

\section{REFERENCES}

1. W. G. Barb, J. Polym. Sci., 37, 515 (1959).

2. K. Nakamura, T. Hatakeyama, and H. Hatakeyama, Kobunshi Ronbunshu, 38, 763 (1981).
3. K. Nakamura, T. Hatakeyama, and H. Hatakeyama, Polymer, 22, 473 (1981).

4. K. Nakamura, T. Hatakeyama, and H. Hatakeyama, Kobunshi Ronbunshu, 39, 53 (1982).

5. K. Nakamura, T. Hatakeyama, and H. Hatakeyama, Polymer, 24, 871 (1983).

6. T. Hatakeyama, K. Nakamura, and H. Hatakeyama, Polymer, 19, 593 (1978).

7. K. Nakamura, T. Hatakeyama, and H. Hatakeyama, Polym. J., 15, 361 (1983).

8. K. Nakamura, T. Hatakeyama, and H. Hatakeyama, Kobunshi Ronbunshu, 39, 765 (1982).

9. H. Hatakeyama, K. Nakamura, and T. Hatakeyama, Pulp Paper Mag. Canada, 6, T105 (1980).

10. H. Hatakeyama, E. Hayashi, and T. Haraguchi, Polymer, 18, 759 (1977).

11. T. Hatakeyama, K. Nakamura, and H. Hatakeyama, Netsusokutei, 6, 50 (1979).

12. T. Hatakeyama, K. Nakamura, and H. Hatakeyama, Polymer, 23, 1801 (1982).

13. I. W. Gilmour and J. N. Haya, Polymer, 19, 281 (1977). 